\title{
AS NOVAS TECNOLOGIAS E O CAMPO DOS SABERES EM ANTROPOLOGIA ${ }^{1}$
}

\author{
Ana Luiza Carvalho da Rocha
}

A complexidade das formas de conhecimento em Antropologia, para além da problemática da era pós-moderna, adquire um sentido novo quando confrontada com novas tecnologias e suas formas mais integrativas, criativas e interativas de geração de conhecimento, seja enquanto veículo de disseminação da cultura contemporânea, seja como objeto de estudo dos tempos e dos espaços sociais daí decorrentes.

Sem dúvida há que dimensionar as recentes descobertas em tecnológica virtual enquanto fenômeno que se integra ao trajeto que instituiu a própria ordem ontológica ou axiológica da estrutura do conhecimento humano, desde seus primórdios, apoiando-se os em estudos já clássicos sobre o assunto.

No caso particular da Antropologia, isto significa não a possibilidade do pesquisador empregar tais recursos advindos do desenvolvimento desta técnica e desta linguagem como suporte-ilustração da argumentação de sua experiência "em campo", mas, principalmente, de aceitar o desafio de gerar novas estruturas narrativas na produção de estudos etnográficos, a partir da exploração de hipertextos que estão para além da escrita alfabética.

Tomando como foco central o espaço de problemas que gera, na construção de narrativas etnográficas, a utilização de novas tecnologias, tratarei, aqui de pensar algumas encruzilhadas epistemológicas daí decorrentes, lugar de onde se descortina os horizontes de uma antropologia no cyberspace.

\footnotetext{
${ }^{1}$ Texto apresentado na Mesa Redonda "Novos rumos de pesquisa na área das tecnologias da imagem retraçando mapas culturais”, no XXIII ENCONTRO ANUAL DA ANPOCS, em Caxambú, Minsa Gerais.
} 
Da transposição da oralidade primária à civilização da escrita, do homem cuja mão formava palavras e pontuava discursos ao nascimento de uma civilização da imagem, a informática obriga cada vez mais o pesquisador contemporâneo a desenvolver formas mais integrativas e criativas de documentação e análise dos suportes materiais onde se deposita o conhecimento da humanidade.

Assim, a incorporação de tecnologias virtuais situa o antropólogo no dilema que origina o próprio fenômeno da disseminação descontinua da modernidade tecnológica no âmbito das ciências humanas.

Entretanto, revela-se aí um despreparo do cientista social no que diz respeito aos usos de formas de produção e geração de conhecimento com base em tecnologias virtuais, sendo que uma das razões para este despreparo reside, justamente, no seu apego às ordens sociais tradicionais de produção de conhecimento nas ciências humanas. Isto é, a ordem "escritural" de sua produção teórico-conceitual.

O que me chama a atenção é, assim, que apesar de dedicar-se ao tratamento analítico do caráter veicular que preside as culturas contemporâneas, o cientista social, não tem incorporado na mesma medida o ritmo de tais transformações no processo de disseminação/produção dos seus saberes científicos.

Mantendo-se aquém deste processo, e de certa forma, imune às conseqüências que a era das tecnologias virtuais desencadeia na forma como se processa o conhecimento do mundo contemporâneo, o cientista social permanece restrito à tecnologia da escrita como forma lapidar de organizar e comunicar suas experiências etnográficas.

Em particular, os antropólogos, tem uma tendência à exaltação do realismo nos jogos da memória que preside o trabalho de campo, quando traduzido para o texto escrito etnográfico. Freqüentemente se esquece que a escrita etnográfica só se torna viável em razão da existência do próprio fenômeno do desencaixe do espaço-tempo que preside as sociedades contemporâneas.

Isto, no mínimo, por duas razões. A primeira, é que a escrita etnográfica se configura através da experiência da "distensão espaço-temporal" vivida pelo antropólogo 
entre o "estar lá" e o "estar aqui”, ou seja, revela o esforço do antropólogo em arranjar, num todo coerente, estruturas espaço-temporais diferenciais - os instantes da experiência vivida em campo e a sua tradução num todo ordenado logicamente. A segunda razão, decorrente da anterior, diz respeito ao processo de "descentração do sujeito" que configura a produção dos saberes em Antropologia onde o fenômeno do desencaixe "espaço/tempo" assume sua forma mais sutil: o afastamento do antropólogo do seu si-mesmo.

Certamente, os saberes antropológicos, como todos os demais construídos pela humanidade, tem suas filiações mitológicas. Sem dúvida, que o formalismo conceptual das análises em Antropologia, e dos seus já clássicos critérios arquivísticos, tendo como suporte a tecnologia da escrita, contempla alguns mitos de fundação do própria configuração dos saberes científicos.

Assim, ao integrar os recursos interativos e integrativos oriundos das novas tecnologias, a matriz disciplinar da Antropologia se acresce de um novo desafio no sentido de compreender o protocolo da linguagem que funda seu campo de estudo.

Retraçando um pouco o percurso do desencaixe das estruturas espaço-temporais da memória no trajeto da conformação do mundo urbano-industrial, em nossas sociedades complexas, pode-se suspeitar que as atuais tecnologias da informática e as redes eletrônicas sejam um dos "lugares" mitológicos atribuídos à apropriação e recriação do seu patrimônio.

Nesta perspectiva, vale lembrar os efeitos produzidos pelo advento da imprensa, em nossas sociedades, uma vez que a partir desta tecnologia o modo de transmissão do conhecimento no Ocidente moderno altera-se, represenanto o surgimento de novas formas de registros, documentação e análise dos fatos da vida social dos quais somos, nós antropólogos, ainda tributários.

Iniciado em fins do séc. XVIII, pode-se dizer, sem medo de errar, assim como as novas tecnologias advindas da informática e as atuais redes digitais, que este processo resulta de inúmeras rupturas dos arranjos que as sociedades humanas estabelecem entre vida 
e matéria. Ou seja, remonta ao processo de liberação da memória de suas bases materiais e físicas, com o surgimento da civilização da escrita no Ocidente. ${ }^{2}$

Particularmente, o advento da impressão resultou de numa mutação nas tecnologias que sustentavam o pensamento do homem ocidental, pela forma como, através dela, os argumentos eram expostos, como por exemplo o predomínio da prosa escrita sob a antiga prosa oral, fruto da tecnologia do manuscrito. ${ }^{3}$

Assim, não é pura erudição se pensar aqui a forma como o advento da imprensa rompeu com os elos tradicionais criados pelas sociedades humanas entre transmissão oral do conhecimento e a escrita do manuscrito, ao possibilitar a recombinação e associações de idéias numa rede de textos incomparavelmente mais ampla que os antigos manuscritos.

A técnica da imprensão possibilitou a cultura da escrita modelar o conhecimento do social às "apresentações sistemáticas de uma matéria especializada, dividida de acordo com um plano coerente", apoiando-se em suas interfaces ("paginação regular, sumários, cabeçalhos aparentes, índice, uso freqüente de tabelas, esquemas e diagramas”). Isto em oposição ao método escolástico, que imitava os métodos de transmissão oral (perguntas e respostas, discussões contra ou a favor). ${ }^{4}$

Prosa escrita, que por sua vez, era tributária de um longo percurso de complexificação de tecnologias que sustentaram a formulação do pensamento humano, e que se iniciou com o surgimento da escrita ideográfica no neolítico, baseada na mnemotécnica da oralidade primária. Conforme alguns autores já anunciaram, dos ideogramas à forma dos antigos manuscritos, a forma de pensar o mundo ocidental alterouse, ajustando-se a oralidade dos cantos, dos mitos e das palavras às circunstâncias de uma civilização da escrita alfabética. ${ }^{5}$

Portanto, o uso novas tecnologias no campo de produção de saberes da Antropologia, não pode prescindir da compreensão do trajeto de hominização do homem.

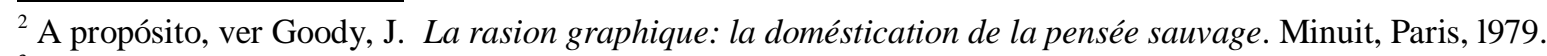
${ }^{3}$ Cf. Levy, P As tecnologias da inteligência. Rio de Janeiro, Editora 34, 1993.

${ }^{4} \mathrm{Cf}$. Serres, M. Atlas, Julliard, Paris, 1994.

${ }^{5}$ Cf. Lafont, H. Anthropologie de l'écriture. CCI, Centre George Pompidou, 1984 e Goody, J. La lógique de l'ecriture: aux origines des sociétés humaines. Armand Colin, Paris, 1984..
} 
Isto é, as "revoluções conceituais" daí resultantes não se afastam, só por serem denominadas de "científicas", do processo que rege a construção do conhecimento humano.

Neste sentido, os estudos em torno das novas tecnologias da informática e das redes eletrônicas, não estão associados somente ao surgimento de novas modalidades de conhecimento, como esta novas formas de conhecer participam da conformação da figura do homem no Ocidente.

Se transladarmos estes comentários para o plano da escritura antropológica quando se observa que nas antigas redes de signos tecida pela escrita do antropólogo - e impressa em moldes monográficos em sua velha máquina de escrever (em substituição as suas anotações manuscritas) - veremos os efeitos da tecnologia da impressão sobre a modalidade de controle simbólico do tempo que preside a narrativa "realista" em Antropologia.

Neste contexto da tecnologia da escrita, acoplada a tecnologia da impressão, veremos o tempo da narrativa etnográfica aparecer cada vez mais linear e histórico, apresentando-se a vida quotidiana dos "nativos" e a experiência do antropólogo em campo como verdades independente dos sujeitos em interação.

É, portanto, graças à tecnologia da escrita e da impressão que a complexa estrutura temporal que envolve o diálogo entre pesquisador e "nativo" se tornou reprodutível, objetivada aos olhos do leitor (e do próprio antropólogo) e, assim, ascendendo ao lugar de objeto suscetível de análise e exame científico por parte da comunidade lingüística dos cientistas sociais. ${ }^{6}$

Não é por acaso que o desafio maior que se apresenta para os antropólogos que investem na incorporação das novas tecnologias em sua "escritura etnográfica", seja o de desembaraçar-se dos sistemas de valores e de crenças que cercam o discurso científico, com base num método de exposição analítico.

\footnotetext{
${ }^{6}$ Ver os comentários contidos na obra de Cardoso de Oliveira, R. Sobre o Pensamento Antropológico. Rio de Janeiro, tempo Brasileiro, 1988.
} 
Dos antigos manuscritos, a Antropologia guarda a sua devoção ao diário de campo e ao método etno-gráfico que segue sendo, salvo as querelas dos pós-modernos, ainda nos dias de hoje, tributário do ambiente cognitivo instaurado pelas primeiras civilizações históricas, ao propagar a idéia de trans-crever o depoimento oral dos "nativos" nos termos do discurso racional da ciência. ${ }^{7}$

Apesar das amarras epistemológicas que perpetuam o saber antropológico no interior dos cânones da civilização da escrita, entretanto, percebe-se, na história da antropologia e mesmo em sua prot-história, a presença de outros fragmentos de significação na construção da obra etnográfica que dialogam com o texto escrito, e que são seguidamente contrapostos aos conteúdos da consciência daquele que a escreve.

A necessidade de antropólogos valerem-se de desenhos, diagramas, fotografias ou filmes, na história da Antropologia, pode revelar alguns dos constrangimentos epistemológicos que levaram o antropólogo, em seu desejo de domesticar o tempo do seu pensamento, a explorar outros ambientes cognitivos como interfaces do seu texto escrito.

Neste sentido, filiada ainda a uma certa tradição do manuscrito no trabalho de campo, as modalidades de conhecimento em Antropologia, dentro dos padrões de uma cultura letrada e erudita, tem timidamente se questionado a respeito do processo de desterritorialização do texto etnográfico, desde suas origens. Da mesma forma, tem se dedicado timidamente a explorar novas possibilidades dos dispositivos de recepção e disseminação de suas representações discursivas e icônicas. ${ }^{8}$

Tradução, interfaces e redes de interfaces colocam o antropólogo, nos dias de hoje, frente a desmaterialização do texto etnográfico. Tal fenômeno deverá conduzir a Antropologia a re-pensar o conjunto de seus textos monográficos como hipertextos multimídia.

\footnotetext{
${ }^{7}$ A respeito ver, por exemplo, Rosaldo, R. Cultura y verdad, nueva propuesta de análisis social. México, Grijalbo, 1989 e Casullo, N. (org) El debate Modernidad Postmodernidad. Buenos Aires, El Cielo pro Asalto, 1993.

${ }^{8}$ Cf. Rheingold, H. La réalité virtuelle. Dunod, Paris, 1993 e Lévy, P. L'intelligence collective. Pour une anthropolgoie du cyberspace. La Découverte, Paris, 1994..
} 
No que tange à obsessão mnemotécnica da civilização da escrita, e com o advento da imprensa, da fotografia, do cinema e do vídeo, pode-se suspeitar que tal complexificação do tratamento e armazenamento de informações sobre culturas e povos pode progressivamente desencadear na Antropologia um novo estilo cognitivo. ${ }^{9}$

Neste caso, certamente se a imagem-síntese vier a ocupar alguma lugar nas produções científicas não será para que ela ser convidada a ocupar um lugar de ornamento no corpo da antiga narrativa que tem como suporte a escrita. Isto é, de demonstração visual da evolução linear dos argumentos apresentados em seqüências lógicas e objetivas de assertivas e argumentação que fundam a tradição da escritura etnográfica. ${ }^{10}$

Tal desafio de inserir os saberes científicos numa era da "democratização da cultura" não é , hoje, apenas tarefa que se impõe ao pesquisador das ciências sociais nos termos do estudo da civilização da imagem da qual o homem contemporâneo faz parte. Trata-se aqui de tarefa que se impõe ao antropólogo na sua busca entendimento do mundo contemporâneo, integrando as tecnologias intelectuais oriundas da informática ao seu hábito mais do que milenar da escrita.

Para finalizar meus comentários, gostaria de referir-me aqui a obra de um pensador René Guénon a propósito dos "signos do tempo no reino da distinção quantitativa" que configura a "mentalidade moderna". Pensar o tema das tecnologias virtuais, da imagem digital no âmbito da produção de saberes das ciências sociais, parece confrontar o conhecimento que aí se processa com os seus sonhos de atingir o aspecto quantitativo, mensurável das ações humanas no mundo, na forma de uma realidade de ordem superior.

Isto porque, traduzidos num "corpo-bit", os caracteres alfabéticos de uma razão gráfica longe de servirem a captura do princípio substancial do pensamento, remontam às suas instâncias qualitativas. As tecnologias virtuais rompem, assim, com o domínio da quantidade contínua projetada para a matéria do pensamento, recolocando-a no plano da potencialidade pura e restituindo ao pensamento seu modo fundamental de criação.

\footnotetext{
${ }^{9}$ France, C. "Pour une anthropologie visuelle". In: Paris, Cahiers de L'Homme, 1979 e Heusch, L de. Cinéma et sciences sociales: panorama du film ethnographique et sociologique. Paris,Unesco, 1982.

${ }^{10}$ Rocha, A.L C da “Antropologia das Formas Sensíveis, entre o visível e o invisível a floração de símbolos". In: Horizontes Antropológicos, Antropologia Visual, No 1, Ano 2, Porto Alegre, EDUFRGS, 1995.
} 
Neste ponto, a aceitação do ato de destruição do princípio de substância atribuído à razão gráfica, isto é da letra reter os atos e os pensamentos humanos, pode significar um processo de realocamento dos "lugares da memória" da escrita no campo de produção de saberes das ciências humanas, única possibilidade de configuração de uma Antropologia no cyberspace, e não apenas do cyberspace.

\section{Referências}

Authier, M e Lévy, P. Les arbres de connaissances. La découverte, Paris, 1992.

Basteson, G. Vers une écologie de l'esprit. Seuil, Paris, 1977

Basteson, G. La Nature et la Pensée. Seuil, Paris, 1984.

Cardoso de Oliveira, R. Sobre o Pensamento Antropológico. Rio de Janeiro, Tempo Brasileiro, 1988.

Ellul, J. La Technique ou l'enjeu du siècle. Armand Collinm Paris, 1954.

France, C. "Pour une anthropologie visuelle". In: Paris, Cahiers de L'Homme, 1979 e Heusch, L de. Cinéma et sciences sociales: panorama du film ethnographique et sociologique. Paris, Unesco, 1982.

Ganascia, J-G. L'ame machine. les enjeux de l'intelligence artificielle. Seuil, Paris, 1990.

Giddens, A. As conseqüências da Modernidade. São Paulo, UNESP, 1991.

Goody, J. La rasion graphique: la doméstication de la pensée sauvage. Minuit, Paris, 1979.

Goody, J. La lógique de l'ecriture: aux origines des sociétés humaines. Armand Colin, Paris, $1984 .$.

Havelock, E. Aux origines de la civilistion écrite en Occident. Maspero, Paris, 1981.

Jeudy, P.H. As memórias do social. RJ, Forense Universtária, 1990.

Lafont, H. Anthropologie de l'écriture. CCI, Centre George Pompidou, 1984

Le Goff, J. Memoria e Historia, Barcelona, Enciclopedia Eunaudi, 1984.

Leroi-Gourhan. La Geste et la Parole. Vol I e II. Paris, Albin-Michel, .

Lévy, P As tecnologias da inteligência. Rio de Janeiro, Editora 34, 1993.

Lévy, P. L'idéographie dynamique vers une imagination artificielle? Paris, La Découverte, 1991.

Lévy, P. L'intelligence collective. Pour une anthropologie du cyberspace. La Découverte, Paris, 1994.

Moles, A. Labyrinthes du vécu, l'espace como matière d'actions, Méridiens, Parais, 1982. Ledrut, P. La forme et le sens dans la société. Méridiens, Paris, 1984

Rheingold, H. La réalité virtuelle. Dunod, Paris, 1993.

Ricoeur, P. Tempo e Narrativa, Tomo I e II. São Paulo, Papirus, 1994.

Sansot, P Poétique de la Ville, Méridiens, Paris, 1988.

Sansot, P Les Formes Sensibles de la Vie Sociale. PUF, Paris, 1986.

Schank, R. The cognitive computer. Addisson-Weslwy Reading, Massachusetts, 1984.

Serres, M. Statues, François Bourin, Paris, 1987. 
Serres, M. Atlas, Julliard, Paris, 1994.

Whitehead, A. N. Aventures d'idées. Le Cerf, Paris, 1993

Yates, F. L'art de la mémoire. Gallimard, Paris, 1975. 